\title{
28 Research Square \\ Health-related Quality of Life in Osteoporosis \\ Patients with and without Fractures in Tehran, Iran
}

\section{Marzieh Rajabi}

Bushehr University of Medical Sciences

Afshin Ostovar

Tehran University of Medical Sciences

Ali Akbari Sari

Tehran University of Medical Sciences

Sayed Mahmoud Sajjadi-Jazi

Tehran University of Medical Sciences

\section{Bagher Larijani}

Tehran University of Medical Sciences

Noushin Fahimfar

Tehran University of Medical Sciences

Rajabali Daroudi ( $\square$ rdaroudi@yahoo.com )

Tehran University of Medical Sciences https://orcid.org/0000-0002-0487-4114

\section{Research Article}

Keywords: Health-related Quality of life, Osteoporosis, Fracture, EQ-5D-5L, Iran.

Posted Date: February 23rd, 2022

DOI: https://doi.org/10.21203/rs.3.rs-1089078/v1

License: (c) (1) This work is licensed under a Creative Commons Attribution 4.0 International License.

Read Full License 


\section{Abstract}

Background: Osteoporosis and related fractures are associated with significant morbidity and reduced Health-related Quality of Life (HRQoL). The objective of this study was to measure the HRQoL of osteoporosis patients in Tehran, the capital city of Iran.

Method: We surveyed a sample of 478 patients with osteoporosis aged over 50 years with and without osteoporotic fractures. Patients with osteoporotic fractures (hip, vertebral, and forearm) admitted to the educational hospitals affiliated to the Tehran University of Medical Sciences-Iran, during 2017 were randomly selected. Patients without osteoporotic fractures were also randomly selected among patients with a definite diagnosis of osteoporosis who were referred to three outpatient clinics in Tehran during 2017. Data were collected using the EQ-5D-5L questionnaire. Statistical differences between patients with and without a history of fracture were tested with Pearson's $\chi 2$ test, Student's t-test and Mann-Whitney Utest. The association between HRQOL and other variables was evaluated using a multiple linear regression model.

Result: The mean $\pm S D$ age of the patient was $67.3 \pm 11.9$ years, and $65 \%$ were women. $A$ hundred and seventeen (23\%) patients had hip fractures, $56(11 \%)$ patients had vertebral fractures, $127(25 \%)$ patients had forearm fractures and $178(40 \%)$ patients had no fractures. The median (interquartile range) values of HRQOL scores of those with hip, vertebral, and forearm fractures and those with no history of fracture were $0.53(0.22), 0.60(0.28), 0.64(0.26)$, and $0.64(0.27)$, respectively. According to the result of multiple regression model there was a significant relationship between the HRQoL scores and gender, marital status, employment status, presence of any chronic illness in addition to osteoporosis and type of fracture.

Conclusion: Osteoporosis and related fractures significantly reduced HRQoL. Due to the significant negative impacts of the osteoporosis on HRQoL and healthcare expenditures, Intervention strategies should be tailored to prevent it and to improve the HRQoL of osteoporosis patients.

\section{Introduction}

Osteoporosis is a common disease among elders, which is associated with decreased bone density and increased risk of bone fractures (1). More than 200 million people with osteoporosis live all around the world, and more than 9 million osteoporotic fractures occur annually(2). It is estimated that the prevalence of osteoporosis was nearly 17\% (95\% confidence interval: 13-22\%) in 2012 in Iran, and its prevalence is on the rise. The higher the age, the higher would be its prevalence (3).

Osteoporosis makes the patients prone to bone fractures, so that even partial traumas may result in fracture (4). Most of the fractures occur in hip, spine, and forearm(5). Fractures cause acute pain, impaired daily activity, and reduced Health-related Quality of Life (HRQoL) (6-9). According to the literature, even those osteoporosis patients who don't experience a bone fracture, have lower HRQoL compared to healthy people (10-12). 
The HRQoL is a multidimensional concept that measures the impacts of a disease on various aspects of health, such as physical, mental, and social (13), which has become a common concept to assess the effectiveness of therapeutic interventions for diseases, including for osteoporosis. There are two types of HRQoL instruments: generic and specific (14). Although specific instruments may have higher sensitivity in measuring the impacts of interventions, but due to their inability to compare, generic instruments apply more commonly to inform decisions about resource allocations.

EQ-5D is one of the most widely used generic preference-based instruments to measure the HRQoL that contains five dimensions: Mobility; Self-care; Usual activities; Pain/discomfort, and Anxiety/depression. five levels were identified in each dimension: No problems; Slight problems; Moderate problems; Severe problems; and incapacity(15).

Due to the aging population, the prevalence of osteoporosis is increasing in many countries, including Iran. However, few studies are conducted to assess the HRQoL of osteoporosis patients in Iran. Therefore, the current study aimed to measure the HRQoL of osteoporosis patients, both with a history of fracture and no fracture in Iran. The results can be used by other researchers to conduct economic evaluation studies as well as making decisions about the allocation of resources for patients with osteoporosis.

\section{Methods}

This is a cross-sectional descriptive study to measure the HRQoL in osteoporosis patients with and without a history of bone fractures.

\section{Study Participants}

The sample consisted of two groups of osteoporosis patients: (a) with a history of common osteoporotic fractures, including hip, vertebral, and forearm fractures, during the previous year before the study; and (b) osteoporosis patients without a history of fracture who were receiving services from outpatient clinics. Subjects of the first group were randomly selected among patients who were referred to the educational hospitals affiliated to Tehran University of Medical Sciences due to common fractures caused by osteoporosis, including hip, vertebral, and forearm fractures. Inclusion criteria were: (1) Fragility fracture of hip, vertebral, or forearm according to the International Classification of Diseases, version 10; (2) Age over 50; (3) a T-score $\leq-2.5 \mathrm{SD}$ in hip or spine.

Subjects of the second group were also randomly selected among patients with a definite diagnosis of osteoporosis who were admitted to three outpatient clinics in Tehran during the year 2017. The inclusion criterion for this group was having a T-Score $\leq-2.5 S D$ in hip or spine and age over 50

\section{Data Collection Tools And Methods}


Data were collected using a questionnaire with two main parts. The first section included demographic questions (about age, gender, marital status, and education level and employment status) and questions about having health insurance and presence of any chronic illness in addition to osteoporosis. The second part was consisted of the Iranian version of EQ-5D-5L questionnaire. The EQ-5D-5L questionnaire contains five dimensions, including mobility, personal care, usual activity, physical pain/discomfort, and anxiety/depression, that each encompasses five levels: No problems; Slight problems; Moderate problems; Severe problems; and incapacity(15). Subjects of the first group, patients with a history of fracture, were interviewed by telephone at least six months after the fracture. For subjects of the second group, no history of fracture, in-person interviews were conducted at the time of patients' referral to the clinics.

\section{Data Analysis}

We made descriptive analysis of our data by calculating frequencies, mean, median, and standard deviation. To calculate the respondents' HRQoL scores according to the EQ-5D-5L questionnaire we used the five level crosswalk-based value set derived from the EQ-5D-3L value set in Iran (16). In order to obtain the Iranian crosswalk-based EQ-5D-5L value set and using a face-to-face time trade-off method, the crosswalk methodology developed by van Hout et al(17) was applied to the Iranian EQ-5D-3L value set (16).

Statistical differences between patients with and without a history of fracture were established with Pearson's $\chi 2$ test, Student's t-test and Mann-Whitney U-test. The association between HRQOL and other variables was evaluated using a multiple linear regression model that included the EQ-5D-5L scores as the dependent variable and the age, sex, marital status, employment status, having health insurance, presence of any chronic illness in addition to osteoporosis and type of fractures as the explanatory variables. Statistical significance level was set at $p<0.05$. Data were analyzed with Stata Ver.14 software.

\section{Results}

The demographic characteristics of the participants by the type of fracture are described in Table 1. In total 478 patients were sampled, among which 178 had no history of any osteoporotic fracture. Among participants, 117,56 , and 127 patients had hip, clinical vertebrae, and forearms fracture, respectively, and $65 \%, 60.7 \%$, and $74 \%$ were women, respectively. The mean and standard deviation (SD) of participants' age were 68.5 ) 10.7(. For patients with hip fracture, the mean age was 73.5 years and, compared to other types of fractures, they had the highest mean age. Nearly $42 \%$ of participants were unmarried and their marital status were single, divorced, and widow. About $96 \%$ of participants had basic health insurance. Around $62 \%$ of participants had at least one chronic illness in addition to osteoporosis. The mean (SD) of years of education was 6.9 (5.7). There were statistical differences between patients with and without a history of fracture in terms of sex, age, employment status, Having complementary health insurance, presence of any other chronic illness in addition to osteoporosis and years of education $(P<0.05)$. 
Table 1

Sociodemographic characteristics of the sample by type of fracture

\begin{tabular}{|c|c|c|c|c|c|c|c|c|c|c|c|}
\hline \multirow{3}{*}{$\begin{array}{l}\text { Categorical } \\
\text { variables }\end{array}$} & \multirow{2}{*}{\multicolumn{2}{|c|}{$\begin{array}{l}\text { Total } \\
\text { participants } \\
(\mathrm{n}=478)\end{array}$}} & \multicolumn{6}{|c|}{ All fractures $(n=300)$} & \multirow{2}{*}{\multicolumn{2}{|c|}{$\begin{array}{l}\text { No } \\
\text { fractures } \\
(n=178)\end{array}$}} & \multirow{3}{*}{$\begin{array}{l}\text { P- } \\
\text { value* }\end{array}$} \\
\hline & & & \multicolumn{2}{|c|}{$\begin{array}{l}\text { Hip Fx } \\
(n=117)\end{array}$} & \multicolumn{2}{|c|}{$\begin{array}{l}\text { Clinical } \\
\text { vertebral Fx } \\
(n=56)\end{array}$} & \multicolumn{2}{|c|}{$\begin{array}{l}\text { Forearm Fx } \\
(n=127)\end{array}$} & & & \\
\hline & $\mathrm{n}$ & $\%$ & $\mathbf{n}$ & $\%$ & $\mathrm{n}$ & $\%$ & $\mathrm{n}$ & $\%$ & $\mathrm{n}$ & $\%$ & \\
\hline \multicolumn{12}{|l|}{ Sex } \\
\hline Men & 124 & 25.9 & 41 & 35.0 & 22 & 39.3 & 33 & 26.0 & 28 & 15.7 & \multirow[t]{2}{*}{$<0.001$} \\
\hline Women & 354 & 74.1 & 76 & 65.0 & 34 & 60.7 & 94 & 74.0 & 150 & 84.3 & \\
\hline \multicolumn{12}{|l|}{ Marital status } \\
\hline Married & 278 & 58.2 & 53 & 45.3 & 34 & 60.7 & 79 & 62.2 & 112 & 62.9 & \multirow[t]{2}{*}{0.10} \\
\hline Unmarried & 200 & 41.8 & 64 & 54.7 & 22 & 39.3 & 48 & 37.8 & 66 & 37.1 & \\
\hline \multicolumn{12}{|c|}{ Employment status } \\
\hline Employment & 27 & 5.6 & 6 & 5.1 & 2 & 3.6 & 9 & 7.1 & 10 & 5.6 & \multirow[t]{4}{*}{0.001} \\
\hline Householder & 281 & 58.8 & 57 & 48.7 & 26 & 46.4 & 82 & 64.6 & 116 & 65.2 & \\
\hline $\begin{array}{l}\text { No } \\
\text { employment }\end{array}$ & 39 & 8.2 & 15 & 12.8 & 8 & 14.3 & 13 & 10.2 & 3 & 1.7 & \\
\hline Retired & 131 & 27.4 & 39 & 33.3 & 20 & 35.7 & 23 & 18.1 & 49 & 27.5 & \\
\hline \multicolumn{12}{|c|}{ Having basic health insurance } \\
\hline Yes & 458 & 95.8 & 116 & 99.1 & 50 & 89.3 & 119 & 93.7 & 173 & 97.2 & \multirow[t]{2}{*}{0.247} \\
\hline No & 20 & 4.2 & 1 & 0.9 & 6 & 10.7 & 8 & 6.3 & 5 & 2.8 & \\
\hline \multicolumn{12}{|c|}{ Having complementary health insurance } \\
\hline Yes & 210 & 44.0 & 35 & 29.9 & 16 & 28.6 & 36 & 28.3 & 123 & 69.5 & \multirow{2}{*}{$\begin{array}{l}- \\
<0.001\end{array}$} \\
\hline No & 267 & 56.0 & 82 & 70.1 & 40 & 71.4 & 91 & 71.7 & 54 & 30.5 & \\
\hline \multicolumn{12}{|c|}{ Presence of any other chronic illness in addition to osteoporosis } \\
\hline Yes & 294 & 61.5 & 68 & 58.1 & 38 & 67.9 & 65 & 51.2 & 123 & 69.1 & \multirow[t]{2}{*}{0.009} \\
\hline No & 184 & 38.5 & 49 & 41.9 & 18 & 32.1 & 62 & 48.8 & 55 & 30.9 & \\
\hline
\end{tabular}

*Between all fractures and no fractures. Student's t-test and Mann-Whitney U-test were used for normal and non-normal distributions, respectively. 


\begin{tabular}{|c|c|c|c|c|c|c|c|c|c|c|c|}
\hline \multirow{3}{*}{$\begin{array}{l}\text { Categorical } \\
\text { variables }\end{array}$} & \multirow{2}{*}{\multicolumn{2}{|c|}{$\begin{array}{l}\text { Total } \\
\text { participants } \\
(n=478)\end{array}$}} & \multicolumn{6}{|c|}{ All fractures $(n=300)$} & \multirow{2}{*}{\multicolumn{2}{|c|}{$\begin{array}{l}\text { No } \\
\text { fractures } \\
(n=178)\end{array}$}} & \multirow{3}{*}{$\begin{array}{l}\text { P- } \\
\text { value* }\end{array}$} \\
\hline & & & \multicolumn{2}{|c|}{$\underset{(n=117)}{\operatorname{Hip} F x}$} & \multicolumn{2}{|c|}{$\begin{array}{l}\text { Clinical } \\
\text { vertebral Fx } \\
(n=56)\end{array}$} & \multicolumn{2}{|c|}{$\begin{array}{l}\text { Forearm Fx } \\
(n=127)\end{array}$} & & & \\
\hline & $n$ & $\%$ & $n$ & $\%$ & $n$ & $\%$ & $n$ & $\%$ & $n$ & $\%$ & \\
\hline $\begin{array}{l}\text { Age (year), } \\
\text { mean (SD) }\end{array}$ & 68.5 & 10.7 & 73.6 & 11.3 & 69.7 & 10.4 & 66.4 & 10.5 & 66.3 & 9.3 & $<0.001$ \\
\hline $\begin{array}{l}\text { Years of } \\
\text { education, } \\
\text { Median } \\
\text { (IQR) }\end{array}$ & 6 & 12 & 6 & 12 & 6 & 12 & 6 & 9 & 9 & 9 & $<0.001$ \\
\hline
\end{tabular}

Distribution of participants based on their answers to the EQ-5D-5L questionnaire, separated by the type of fracture, is provided in Table 2. For those with hip, vertebral, and forearm fractures, the percentage of those with "no problems" in the mobility dimension was $4.3 \%, 10.7 \%$, and $30.7 \%$, respectively. This figure for patient with no fracture was $25.3 \%$. About $9.4 \%$ of patients with hip fractures were unable to walk. While $1.8 \%$ and $2.4 \%$ of patients with vertebral and forearm fractures, respectively, and $0 \%$ of patients with no fracture were not able to walk.

In the self-care dimension, $27.4 \%, 35.7 \%$, and $48 \%$ of patients with hip, vertebral, and forearm fractures reported, "no problem" respectively, while $60.1 \%$ of patients with no fracture reported "no problem". Besides, $6 \%, 1.8 \%, 1.6 \%$, and $0 \%$ were not able to wash themselves or wear clothes, respectively.

Regarding the usual activities dimension, $35.9 \%, 39.3 \%, 52.8 \%$, and $60.7 \%$ of those with the hip, vertebral, forearms fractures and those without a history of fracture had "no problem" in doing their usual activities, respectively. Besides, $6.0 \%, 3.6 \%, 0.8 \%$, and $0.6 \%$ were unable to perform usual activities.

In the Pain/discomfort dimension $5.1 \%, 5.4 \%, 7.1 \%$, and $12.9 \%$ of those with a history of hip, vertebral, and forearm fracture, and those without a history of fracture reported "no pain and physical discomfort", respectively. Besides, $8.6 \%, 14.3 \%, 9.5 \%$, and $9 \%$, respectively, noted that they had infinite pain or physical discomfort.

In terms of anxiety/depression, the percentage of those with a history of hip, vertebral, and forearm fracture and those with no history of fracture who reported "no anxiety or depression" was $35 \%, 26.8 \%$, $30.7 \%$, and $37.1 \%$, respectively. Furthermore, $6.8 \%, 5.4 \%, 5.5 \%$, and $6.2 \%$, respectively, reported extreme anxiety or depression.

There were statistical differences between patients with a history of fracture, and those without a history of fracture in terms of distribution of their answers to the EQ-5D-5L questions in the mobility, self-care and usual activities dimensions $(P<0.05)$. 
Table 2

Frequency of item responses in each EQ-5D-5L dimension by type of fracture

\begin{tabular}{|c|c|c|c|c|c|c|c|c|c|}
\hline \multirow[t]{3}{*}{ Dimension } & \multicolumn{6}{|c|}{ All fractures $(n=300)$} & \multirow{2}{*}{\multicolumn{2}{|c|}{$\begin{array}{l}\text { No fracture } \\
(n=178)\end{array}$}} & \multirow{3}{*}{$\begin{array}{l}\text { P- } \\
\text { value* }\end{array}$} \\
\hline & \multicolumn{2}{|c|}{$\underset{(n=117)}{\operatorname{Hip} F x}$} & \multicolumn{2}{|c|}{$\begin{array}{l}\text { Clinical vertebral } \\
\text { FX }(n=56)\end{array}$} & \multicolumn{2}{|c|}{$\begin{array}{l}\text { Forearm Fx } \\
(n=127)\end{array}$} & & & \\
\hline & $\mathrm{n}$ & $\%$ & $\mathrm{n}$ & $\%$ & $\mathrm{n}$ & $\%$ & $\mathrm{n}$ & $\%$ & \\
\hline \multicolumn{10}{|l|}{ Mobility } \\
\hline No problems & 5 & 4.3 & 6 & 10.7 & 39 & 30.7 & 45 & 25.3 & \multirow[t]{5}{*}{0.001} \\
\hline Slight problems & 44 & 37.6 & 23 & 41.1 & 49 & 38.6 & 76 & 42.7 & \\
\hline $\begin{array}{l}\text { Moderate } \\
\text { problems }\end{array}$ & 40 & 34.2 & 16 & 28.6 & 27 & 21.3 & 31 & 17.4 & \\
\hline Severe problems & 17 & 14.5 & 10 & 17.9 & 9 & 7.1 & 26 & 14.6 & \\
\hline Incapacity & 11 & 9.4 & 1 & 1.8 & 3 & 2.4 & 0 & 0.0 & \\
\hline \multicolumn{10}{|l|}{ Self-care } \\
\hline No problems & 32 & 27.4 & 20 & 35.7 & 61 & 48.0 & 107 & 60.1 & \multirow[t]{5}{*}{$<0.001$} \\
\hline Slight problems & 46 & 39.3 & 21 & 37.5 & 42 & 33.1 & 48 & 27.0 & \\
\hline $\begin{array}{l}\text { Moderate } \\
\text { problems }\end{array}$ & 21 & 18.0 & 10 & 17.9 & 19 & 15.0 & 19 & 10.7 & \\
\hline Severe problems & 11 & 9.4 & 4 & 7.1 & 3 & 2.4 & 4 & 2.2 & \\
\hline Incapacity & 7 & 6.0 & 1 & 1.8 & 2 & 1.6 & 0 & 0 & \\
\hline \multicolumn{10}{|l|}{ Usual activities } \\
\hline No problems & 42 & 35.9 & 22 & 39.3 & 67 & 52.8 & 108 & 60.7 & \multirow[t]{5}{*}{$<0.001$} \\
\hline Slight problems & 32 & 27.4 & 19 & 33.9 & 33 & 26.0 & 43 & 24.2 & \\
\hline $\begin{array}{l}\text { Moderate } \\
\text { problems }\end{array}$ & 24 & 20.5 & 7 & 12.5 & 18 & 14.2 & 23 & 12.9 & \\
\hline Severe problems & 12 & 10.3 & 6 & 10.7 & 8 & 6.3 & 3 & 1.7 & \\
\hline Incapacity & 7 & 6.0 & 2 & 3.6 & 1 & 0.8 & 1 & 0.6 & \\
\hline
\end{tabular}

*Between All fractures and no fractures

The median, interquartile range (IQR), and distribution of HRQoL, measured using the EQ-5D-5L and separated by the type of fracture and sex, are provided in Table 3 and figure 1, respectively. The median (IQR) value of HRQoL scores of those with a history of hip, vertebral, and forearm fracture and no history of fracture were $0.53(0.22), 0.60(0.28), 0.64(0.26)$, and $0.64(0.27)$, respectively. The HRQoL scores in women was significantly lower than men $(p=0.003)$. 


\begin{tabular}{|c|c|c|c|c|c|c|c|c|c|}
\hline \multirow[t]{3}{*}{ Dimension } & \multicolumn{6}{|c|}{ All fractures $(n=300)$} & \multirow{2}{*}{\multicolumn{2}{|c|}{$\begin{array}{l}\text { No fracture } \\
(n=178)\end{array}$}} & \multirow{3}{*}{$\begin{array}{l}\text { P- } \\
\text { value* }\end{array}$} \\
\hline & \multicolumn{2}{|c|}{$\underset{(n=117)}{\text { Hip Fx }}$} & \multicolumn{2}{|c|}{$\begin{array}{l}\text { Clinical vertebral } \\
\text { Fx }(n=56)\end{array}$} & \multicolumn{2}{|c|}{$\begin{array}{l}\text { Forearm Fx } \\
(n=127)\end{array}$} & & & \\
\hline & $\mathrm{n}$ & $\%$ & $\mathrm{n}$ & $\%$ & $\mathrm{n}$ & $\%$ & $\mathbf{n}$ & $\%$ & \\
\hline \multicolumn{10}{|c|}{ Pain/discomfort } \\
\hline No & 6 & 5.1 & 3 & 5.4 & 9 & 7.1 & 23 & 12.9 & \multirow[t]{5}{*}{0.056} \\
\hline Slight & 41 & 35.0 & 16 & 28.6 & 37 & 29.1 & 43 & 24.2 & \\
\hline Moderate & 40 & 34.2 & 18 & 32.1 & 40 & 31.5 & 54 & 30.3 & \\
\hline Severe & 20 & 17.1 & 11 & 19.6 & 29 & 22.8 & 42 & 23.6 & \\
\hline Extreme & 10 & 8.6 & 8 & 14.3 & 12 & 9.5 & 16 & 9.0 & \\
\hline \multicolumn{10}{|c|}{ Anxiety/depression } \\
\hline No & 41 & 35.0 & 15 & 26.8 & 39 & 30.7 & 66 & 37.1 & \multirow[t]{5}{*}{0.408} \\
\hline Slight & 35 & 29.9 & 13 & 23.2 & 42 & 33.1 & 44 & 24.7 & \\
\hline Moderate & 22 & 18.8 & 12 & 21.4 & 28 & 22.1 & 30 & 16.9 & \\
\hline Severe & 11 & 9.4 & 13 & 23.2 & 11 & 8.7 & 27 & 15.2 & \\
\hline Extreme & 8 & 6.8 & 3 & 5.4 & 7 & 5.5 & 11 & 6.2 & \\
\hline \multicolumn{10}{|c|}{ *Between All fractures and no fractures } \\
\hline \multicolumn{10}{|c|}{$\begin{array}{l}\text { The median, interquartile range (IQR), and distribution of } \mathrm{HRQ} \text {, } \text {, measured using the EQ-5D-5L and } \\
\text { separated by the type of fracture and sex, are provided in Table } 3 \text { and figure } 1 \text {, respectively. The } \\
\text { median (IQR) value of HRQoL scores of those with a history of hip, vertebral, and forearm fracture and } \\
\text { no history of fracture were } 0.53(0.22), 0.60(0.28), 0.64(0.26) \text {, and } 0.64(0.27) \text {, respectively. The } \\
\text { HRQoL scores in women was significantly lower than men }(p=0.003) \text {. }\end{array}$} \\
\hline
\end{tabular}


Table 3

Median (IQR) of EQ-5D-5L scores by type of fracture

\begin{tabular}{|lllll|}
\hline Type of fracture & All participants & Men & women & \multirow{2}{*}{ P value } \\
\cline { 2 - 4 } & Median (IQR*) & Median (IQR) & Median (IQR) & \\
\hline Hip & $0.53(0.22)$ & $0.60(0.28)$ & $0.52(0.21)$ & 0.034 \\
\hline Clinical Vertebral & $0.60(0.28)$ & $0.62(0.12)$ & $0.50(0.30)$ & 0.064 \\
\hline Forearm & $0.64(0.26)$ & $0.67(0.25)$ & $0.62(0.24)$ & 0.448 \\
\hline No Fracture & $0.64(0.27)$ & $0.74(0.16)$ & $0.62(0.27)$ & 0.002 \\
\hline Total & $0.61(0.24)$ & $0.68(0.25)$ & $0.59(0.24)$ & 0.003 \\
\hline *IQR: interquartile range & & & \\
\hline
\end{tabular}

The mean of responses in each EQ-5D_5L dimension based on fracture types and sex are presented in figure 2. Almost in all dimension, the patients with a history of hip fracture had the highest and those without a history of fracture had the lowest mean. Furthermore, in all dimension the mean of responses were higher in women than men.

Table 4 shows the associates of the quality of life in a multiple linear regression analyses. The results showed that compared to the osteoporotic patients without history of fractures, quality of life was significantly lower in patients with hip fracture (beta $=-0.077, p$-value $<0.001$ ) and vertebral fracture (beta= -0.075 , $p$-value $=0.005)$, but not in patients with forearm fracture (beta $=-0.010$, $p$-value: 0.611 ).

Being married at the time of the study had significant positive association with the quality of life (beta $=0.054, p$-value $=0.002$ ), while a negative association was detected between the presence of a chronic disease and quality of life in patients under study (beta $=-0.033$, $p$-value $=0.039$ ).

Women with complementary health insurance also tended to have higher quality of life, though not statistically significant $($ beta $=0.032, \mathrm{p}$ value $=0.071)$. 
Table 4

The associates of quality of life in the linear regression model

\begin{tabular}{|c|c|c|c|}
\hline \multirow[t]{2}{*}{ Independent variables } & \multicolumn{3}{|c|}{ Dependent variable: utility scores } \\
\hline & Coefficient & Standard Error & P-value \\
\hline Age & -0.001 & 0.001 & 0.098 \\
\hline \multicolumn{4}{|l|}{ Gender } \\
\hline Male & Ref & & \\
\hline Female & $-0.059 *$ & 0.026 & 0.023 \\
\hline \multicolumn{4}{|l|}{ Marital status } \\
\hline Never married, divorced or widowed & Ref & & \\
\hline Married & $0.054^{\star}$ & 0.018 & 0.002 \\
\hline \multicolumn{4}{|l|}{ Employment status } \\
\hline Unemployed & Ref & & \\
\hline Employed & $0.088^{*}$ & 0.043 & 0.042 \\
\hline Home maker & $0.098^{*}$ & 0.036 & 0.007 \\
\hline Retired & $0.137^{*}$ & 0.033 & $<0.001$ \\
\hline Having basic health insurance & -0.010 & 0.040 & 0.801 \\
\hline Having complementary health insurance & 0.032 & 0.017 & 0.071 \\
\hline Presence of any other chronic illness & -0.033 & 0.016 & 0.039 \\
\hline \multicolumn{4}{|l|}{ Type of fracture } \\
\hline No Fracture & Ref & & \\
\hline Hip & -0.077 & 0.022 & $<0.001$ \\
\hline Clinical Vertebral & -0.075 & 0.027 & 0.005 \\
\hline Forearm & -0.010 & 0.020 & 0.611 \\
\hline
\end{tabular}

\section{Discussion}

In the current study, the HRQoL of those with osteoporotic fractures of the hip, vertebrae, and forearms as well as patients suffering osteoporosis with no history of fractures, was measured using the EQ-5D questionnaire. The median (IQR) values of HRQOL scores of those with hip, vertebral, and forearm fractures and those with no history of fracture were $0.53(0.22), 0.60(0.28), 0.64(0.26)$, and $0.64(0.27)$, respectively. According to the result of multiple regression model there was a significant association 
between the HRQoL scores and gender, marital status, employment status, presence of any chronic illness and type of fracture.

Almost $95.7 \%$ of patients with hip fracture had mobility problems, $72.6 \%$ had self-care problems, $64.1 \%$ had problems with usual activities, $94.9 \%$ had pain/discomfort, and $65 \%$ had anxiety/depression.

Compared to other fractures, hip fracture causes the most disability. Nearly 10 to $20 \%$ of people who have a hip fracture die within the next year and about half of them lose their ability to perform usual activities (18). Almost 40 to $60 \%$ of patients with a history of hip fracture regain their full mobility. About $20-60 \%$ of people who had no problem in doing their personal activities before the fracture needed help in doing their activities for more than one year after the fracture $(19,20)$.

Based on a study conducted in Russia, the HRQoL of people with a history of hip fractures two weeks after the fracture was -0.22 , four months after the fracture was $0.39,12$ months later increased to 0.46 , and was 0.64 eighteen months after the fracture (21). Another study that measured the HRQoL of people with a history of hip fracture in Sweden reported that four months after the fracture, the HRQoL was 0.18, and this number increased to 0.62 four months later, and reached 0.6712 months later (22). Besides, the results of a new study in Spain reported that HRQoL of people over the age of 65 , a month after the fracture was 0.16 (23). Another study reported that the HRQoL of those with hip fractures was 0.64 (24).

The results of the study in Spain on elderly patients with a history of hip fracture showed that one month after fracture $99.5 \%$ of patients had problems in mobility, $98.2 \%$ in self-care, $99.1 \%$ in doing usual activities, $85.4 \%$ in pain/discomfort, and $53 \%$ in anxiety/depression (23). Besides, a study conducted in Russia revealed that $83 \%$ of patients with hip fracture had problems in mobility, $71 \%$ in self-care, $73 \%$ in doing usual activities, $28 \%$ in pain/discomfort, and $15 \%$ in anxiety/depression (21).

Vertebral fracture is also common among patients with osteoporosis (5). Various studies found that vertebral fracture decreases HRQoL (25). Hagino et al. conducted a study to estimate the HRQoL changes in patients with vertebral fractures and reported that two weeks after the fracture the HRQoL was 0.53 , three months later it increased to 0.75 , six months later it was 0.74 , and one year after the fracture this number was was 0.83 (26). Another study that estimated HRQoL of patients with a history of vertebral fracture in Sweden reported that after the fracture, the HRQoL was 0.18 , four months later it increased to 0.47 , and 12 months later it was 0.49 (22). In the current study, the HRQoL of patients with vertebral fracture was 0.55 . A systematic review and meta-analysis conducted by Al-Sari et al. revealed that the physical dimension of HRQoL of osteoporosis patients with vertebral fracture was significantly lower than HRQoL of osteoporosis patients without a history of vertebral fracture. However, in terms of the mental dimension of HRQoL, no significant difference was overserved between two groups (14). In the current study also the HRQoL of patients with a history of vertebral fracture was significantly lower than patients with no history of fracture. For example, $89.4 \%$ of patients with vertebral fracture had problems in mobility, while $72 \%$ of patients with no history of fracture had such a problem. Moreover, 64.3 and $37.5 \%$ of patients with vertebral fracture and without a history of fracture had problems in self-care, 
respectively. According to the result of the multiple regression model in our study, the HRQoL scores in patients with clinical vertebral fractures was 0.075 less than patients without a history of fracture.

Among the most common osteoporotic fractures, patients with a forearm fracture have the highest HRQoL. In a Swedish study, the HRQoL of people with a forearm fracture was 0.56 after the fracture, four months later it was 0.82 , and 12 months after the fracture it was 0.86 (22). Another study conducted in Korean reported that the HRQoL of those with a forearm fracture was $0.83(27)$. In the current study, the median score of HRQoL of patients with forearm fracture was 0.64 .

Daroudi et al. measured the HRQoL of the general population aged 60 to 69 years using the EQ-5D-5L questionnaire in Iran and reported that the mean score of HRQoL was 0.74 (28). In the current study, the mean age of patients with no history of fracture was nearly 66.3 years, and the median value of HRQoL score was 0.64 , which indicates that the HRQoL of osteoporosis patients with no history of fracture is lower than healthy individuals. Wilson et al. also reported that osteoporosis alone has negative effects on the HRQoL (12).

In the current study, the EQ-5D-5I questionnaire, which is the most widely used general preference-based instrument to measure the HRQoL, was used to measure the HRQoL of patients with osteoporosis and common fractures in Iran (29). Other researchers and/or policymakers can use the results of this study to conduct economic evaluation studies and to provide information for decision making regarding resource allocations. However, the study also had limitations. In the current study, the HRQoL of patients with osteoporotic fractures was measured between six months and one year after the fracture. Given that the HRQoL of these patients usually changes during the first year after the fracture, therefore the results cannot be generalized to the first six months after the fracture. Besides, patients with osteoporotic fractures were sampled from hospitals and therefore the results cannot be generalized to outpatients. Although this limitation was more for vertebral and forearm fractures, as almost all patients with hip fractures are hospitalized.

\section{Conclusion}

According to the findings, osteoporosis and osteoporotic fractures significantly reduced the HRQoL. Since Iran's population is aging, age-related health conditions such as osteoporosis are increasing. Due to the significant negative impacts of the osteoporosis on HRQoL and healthcare expenditures, it is necessary to design interventions to prevent it and to improve the HRQoL of patients with osteoporosis.

\section{Abbreviations}

HRQoL

Health-Related Quality of Life

\section{Declarations}




\section{Ethics approval and consent to participate:}

This study was approved by the ethics committee of the Deputy of Research and Technology of the Tehran University of Medical Sciences (IR.TUMS.EMRI.REC.1396.0016). The participants were assured that their information would remain confidential. Informed consent was obtained from all individual participants included in the study. Verbal consent was obtained from participants who completed the survey over the telephone, and written consent was obtained from patients who were interviewed in person.

Consent for publication: Not applicable.

Availability of data and materials: The datasets used and/or analyzed during the current study are available from the corresponding author on reasonable request.

Competing Interests: The authors declare they have no conflict of interests.

Funding: This study was funded by Tehran University of Medical Sciences (grant number 9611119004).

Authors' contributions: All authors contributed to the study conception and design. Material preparation, data collection, and analysis were performed by RD, MR, AO, AS, SMS-J, NF, and BL. The first draft of the manuscript was written by RD and MR and all authors commented on previous versions of the manuscript. All authors read and approved the final manuscript.

Acknowledgements: Not applicable.

Authors' information: Not applicable.

\section{References}

1. Lee Y-K, Kim H-J, Park JW, Won S, Hwang J-S, Ha Y-C, et al. Transcultural adaptation and psychometric properties of the Korean version of the Quality of Life Questionnaire of the European Foundation for Osteoporosis (QUALEFFO-41). Archives of osteoporosis. 2019;14(1):96.

2. Pisani P, Renna MD, Conversano F, Casciaro E, Di Paola M, Quarta E, et al. Major osteoporotic fragility fractures: Risk factor updates and societal impact. World journal of orthopedics. 2016;7(3):171.

3. Irani AD, Poorolajal J, Khalilian A, Esmailnasab N, Cheraghi Z. Prevalence of osteoporosis in Iran: A meta-analysis. Journal of research in medical sciences: the official journal of Isfahan University of Medical Sciences. 2013;18(9):759.

4. Millennium WSGotBoMCatSotN, Organization WH. The burden of musculoskeletal conditions at the start of the new millennium: report of a WHO Scientific Group: World Health Organization; 2003.

5. Cooper C, Dennison EM, Leufkens HG, Bishop N, van Staa TP. Epidemiology of childhood fractures in Britain: a study using the general practice research database. Journal of Bone and Mineral Research. 2004;19(12):1976-81. 
6. Borgström F, Lekander I, Ivergård M, Ström O, Svedbom A, Alekna V, et al. The International Costs and Utilities Related to Osteoporotic Fractures Study (ICUROS) - quality of life during the first 4 months after fracture. Osteoporosis international. 2013;24(3):811-23.

7. Cook DJ, Guyatt GH, Adachi JD, Clifton J, Griffith LE, Epstein RS, et al. Quality of life issues in women with vertebral fractures due to osteoporosis. Arthritis \& Rheumatism: Official Journal of the American College of Rheumatology. 1993;36(6):750-6.

8. Lips P, van Schoor NM. Quality of life in patients with osteoporosis. Osteoporosis international. 2005;16(5):447-55.

9. Martin A, Sornay-Rendu E, Chandler J, Duboeuf F, Girman C, Delmas P. The impact of osteoporosis on quality-of-life: the OFELY cohort. Bone. 2002;31(1):32-6.

10. Ciubean AD, Ungur RA, Irsay L, Ciortea VM, Borda IM, Onac I, et al. Health-related quality of life in Romanian postmenopausal women with osteoporosis and fragility fractures. Clinical interventions in aging. 2018;13:2465.

11. Bianchi ML, Orsini MR, Saraifoger S, Ortolani S, Radaelli G, Betti S. Quality of life in post-menopausal osteoporosis. Health and quality of life outcomes. 2005;3(1):78.

12. Wilson S, Sharp C, Davie M. Health-related quality of life in patients with osteoporosis in the absence of vertebral fracture: a systematic review. Osteoporosis international. 2012;23(12):2749-68.

13. Varni JW, Burwinkle TM, Seid M, Skarr D. The PedsQL ${ }^{\mathrm{TM} *} 4.0$ as a pediatric population health measure: feasibility, reliability, and validity. Ambulatory pediatrics. 2003;3(6):329-41.

14. Al-Sari U, Tobias J, Clark E. Health-related quality of life in older people with osteoporotic vertebral fractures: a systematic review and meta-analysis. Osteoporosis International. 2016;27(10):2891900.

15. van Reenen $M$, Janssen B. EQ-5D-5L user guide. basic information on how to use the EQ-5D-5L instrument. Rotterdam, the Netherlands: EuroQOL Research Foundation, 2015. 2017.

16. Goudarzi R, Sari AA, Zeraati H, Rashidian A, Mohammad K, Amini S. Valuation of Quality Weights for EuroQol 5-Dimensional Health States With the Time Trade-Off Method in the Capital of Iran. Value in health regional issues. 2019;18:170-5.

17. van Hout B, Janssen M, Feng Y-S, Kohlmann T, Busschbach J, Golicki D, et al. Interim scoring for the EQ-5D-5L: mapping the EQ-5D-5L to EQ-5D-3L value sets. Value in health. 2012;15(5):708-15.

18. Lewiecki EM, Chastek B, Sundquist K, Williams SA, Weiss R, Wang $Y$, et al. Osteoporotic fracture trends in a population of US managed care enrollees from 2007 to 2017. Osteoporosis International. 2020:1-6.

19. Dyer SM, Crotty M, Fairhall N, Magaziner J, Beaupre LA, Cameron ID, et al. A critical review of the long-term disability outcomes following hip fracture. BMC geriatrics. 2016;16(1):158.

20. Magaziner J, Hawkes W, Hebel JR, Zimmerman SI, Fox KM, Dolan M, et al. Recovery from hip fracture in eight areas of function. The Journals of Gerontology Series A: Biological Sciences and Medical Sciences. 2000;55(9):M498-M507. 
21. Lesnyak O, Svedbom A, Belova K, Dobrovolskaya O, Ershova O, Golubev G, et al. Quality of life after fragility fracture in the Russian Federation: results from the Russian arm of the International Cost and Utility Related to Osteoporotic Fractures Study (ICUROS). Archives of Osteoporosis. 2020;15(1):1-9.

22. Borgström F, Zethraeus N, Johnell O, Lidgren L, Ponzer S, Svensson O, et al. Costs and quality of life associated with osteoporosis-related fractures in Sweden. Osteoporosis International. 2006;17(5):637-50.

23. Amarilla-Donoso FJ, López-Espuela F, Roncero-Martín R, Leal-Hernandez O, Puerto-Parejo LM, AliagaVera I, et al. Quality of life in elderly people after a hip fracture: a prospective study. Health and quality of life outcomes. 2020;18(1):1-10.

24. Adachi JD, Adami S, Gehlbach S, Anderson Jr FA, Boonen S, Chapurlat RD, et al., editors. Impact of prevalent fractures on quality of life: baseline results from the global longitudinal study of osteoporosis in women. Mayo Clinic Proceedings; 2010: Elsevier.

25. Hall S, Criddle RA, Comito T, Prince R. A case-control study of quality of life and functional impairment in women with long-standing vertebral osteoporotic fracture. Osteoporosis International. 1999;9(6):508-15.

26. Hagino H, Nakamura T, Fujiwara S, Oeki M, Okano T, Teshima R. Sequential change in quality of life for patients with incident clinical fractures: a prospective study. Osteoporosis international. 2009;20(5):695-702.

27. Kwon $\mathrm{H}-\mathrm{Y}, \mathrm{Ha} \mathrm{Y}-\mathrm{C}, \mathrm{Yoo} \mathrm{J}-\mathrm{I}$. Health-related quality of life in accordance with fracture history and comorbidities in Korean patients with osteoporosis. Journal of bone metabolism. 2016;23(4):199206.

28. Emrani Z, Akbari Sari A, Zeraati H, Olyaeemanesh A, Daroudi R. Health-related quality of life measured using the EQ-5D-5 L: population norms for the capital of Iran. Health and Quality of Life Outcomes. 2020;18:1-8.

29. Brazier J, Ara R, Rowen D, Chevrou-Severac H. A review of generic preference-based measures for use in cost-effectiveness models. Pharmacoeconomics. 2017;35(1):21-31.

\section{Figures}




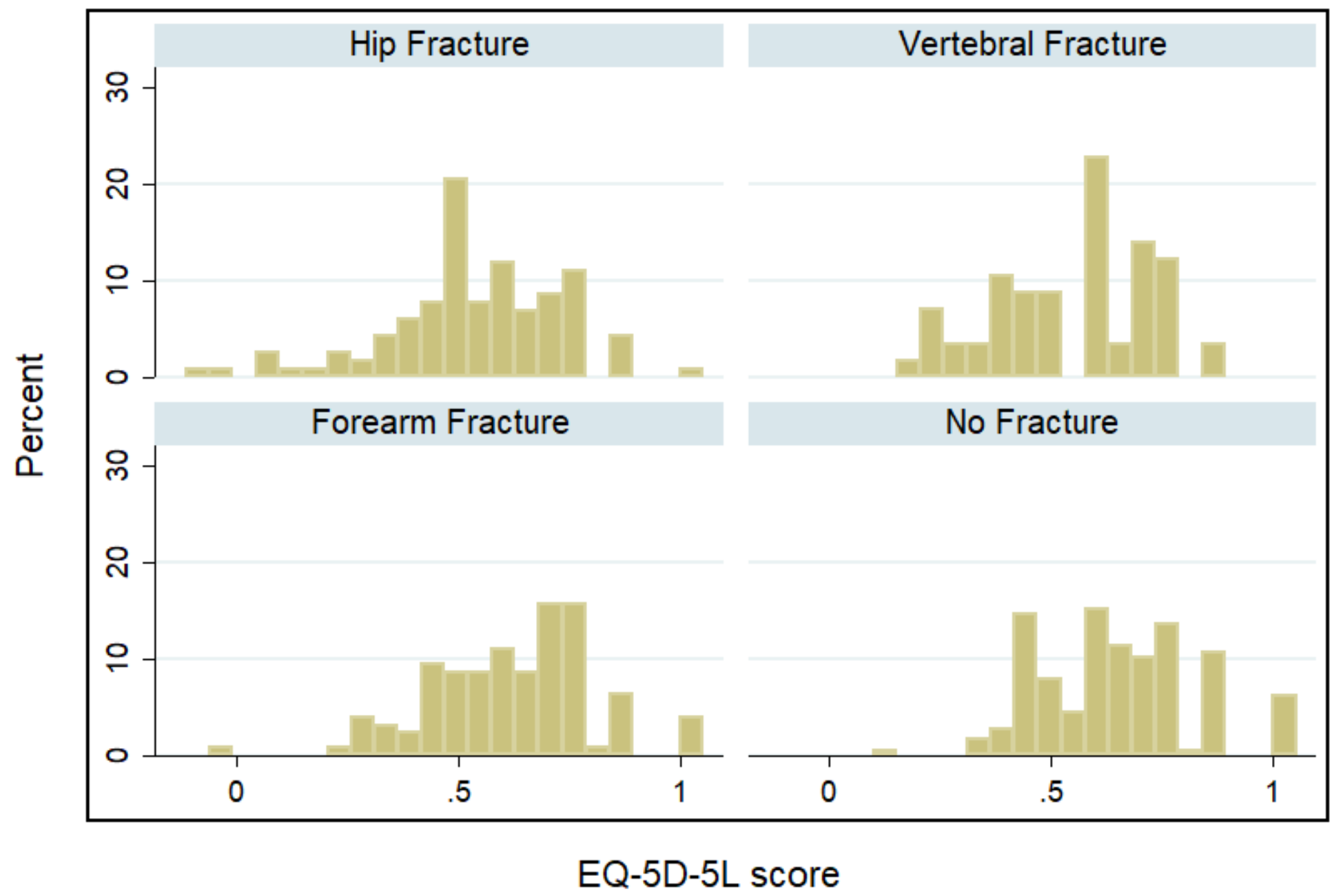

Figure 1

Distribution of the EQ-5D-5L scores by type of fracture 
14

12

10

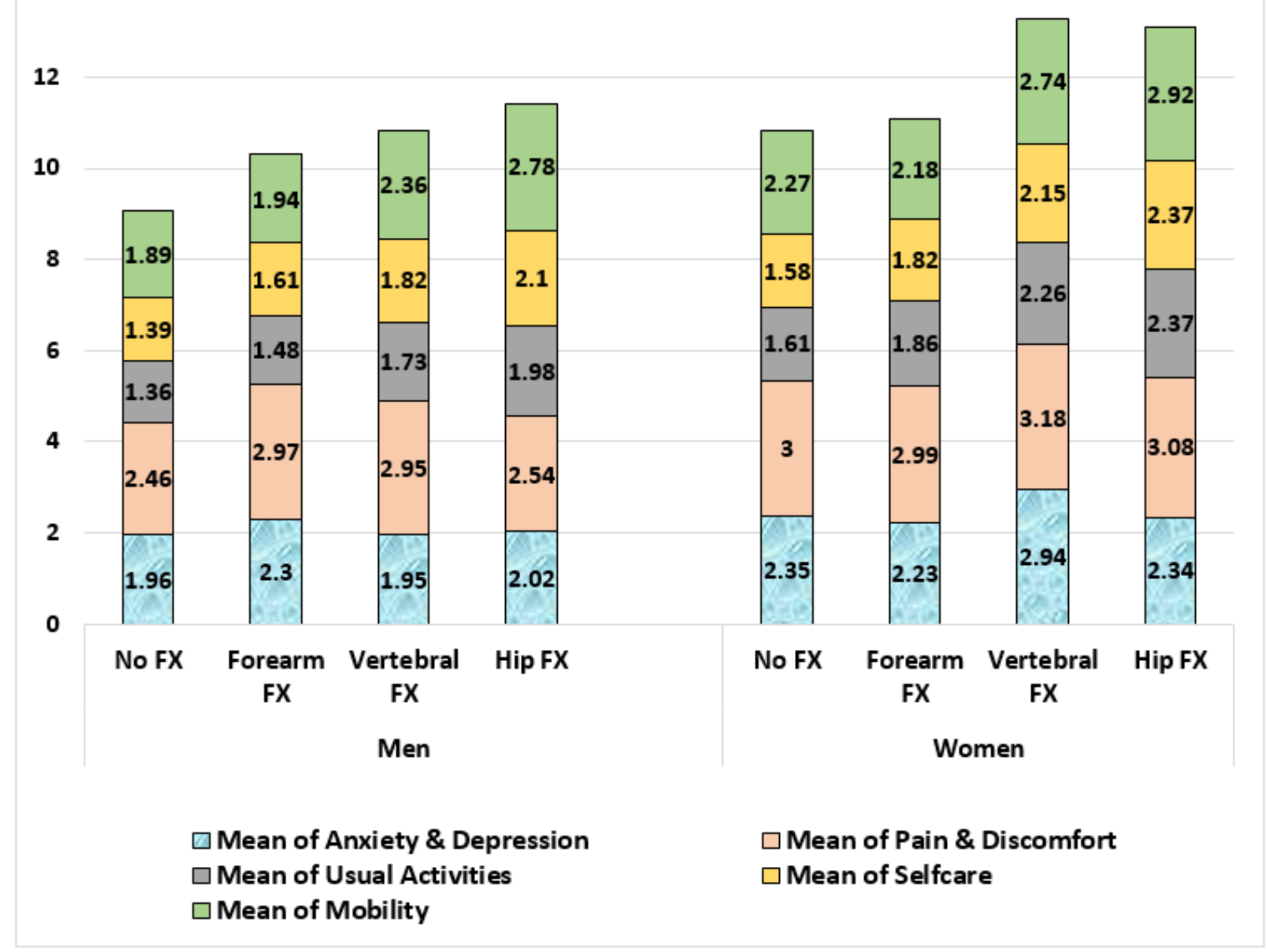

Figure 2

The mean of responses in each EQ-5D_5L dimension based on fracture types and sex 